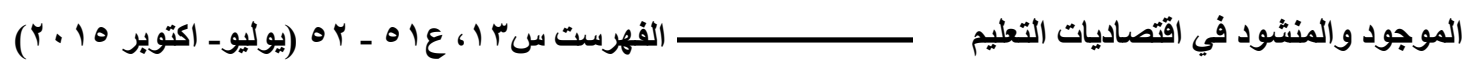

\title{
الموجود والمنشود في اقتصاديات التعليم
}

\section{عرض \\ آمنه فهمى محمود

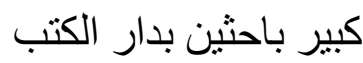

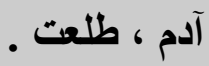

الموجود والمنشود في اقتصـاديات

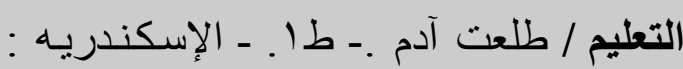

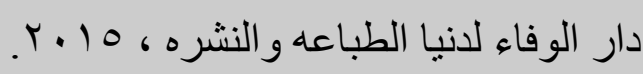

(100

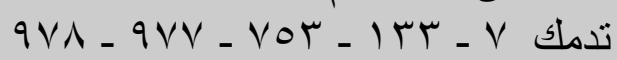

يزيد حدة المشكلة، ونو عية التعليم الذي يريده

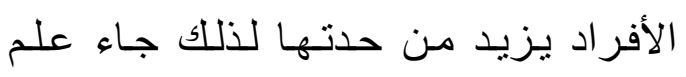
اقتصاديات التعليم ليتعامل مع تللك المشكلة. وتعريف اقتصاديات التعليم هي تحليل

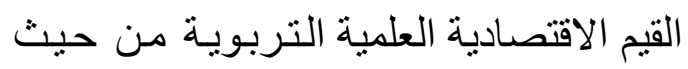

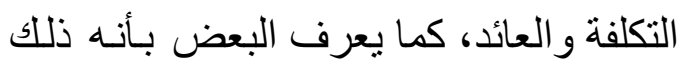

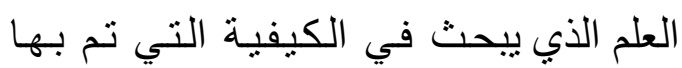
توزيع الموارد المتاحة، والموجهة للعملية لإنية

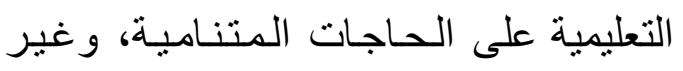
المنتهية على التعليم بكفاءة لإشباع أكبر قدر

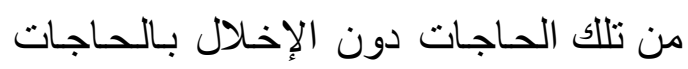
التربوية ؛ وهو التوظيف الأمثل للإمكانيات

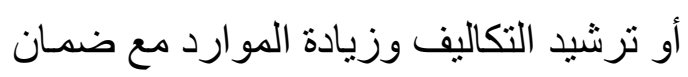
الجودة وتتويع مصادر التمويل للمشرو عات التئ
إن علم اقتصاديات التعليم من العلوم

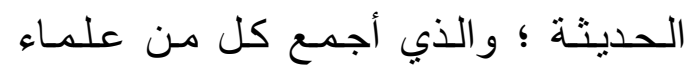
الاقتصاد و علماء التربية على أهمبة هذا كلية علهاه

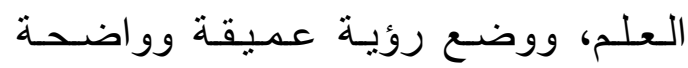

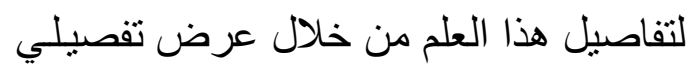
لتاريخ نشأة اقتصاديات التعليم و التربية، وتطوره و المشكلة الاقتصساديه في التعليم

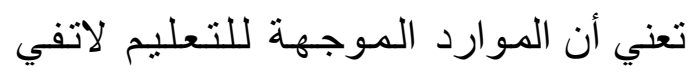

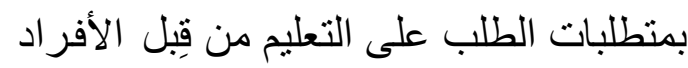

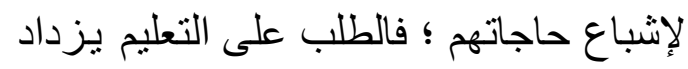

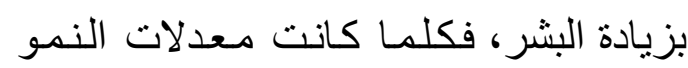

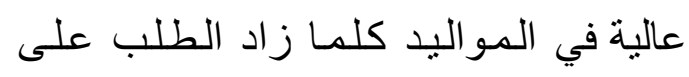
التعليم، وكذلك تطعات أولياء الأمور للوصول بأبنائهم إلى اقصى مر احل التعليم 
اقتصادية التعليم :

ا ـ دور التربية المتز ايد في دفع عملية

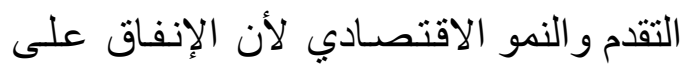

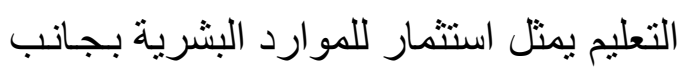

كونه خدمة استهلاكية.

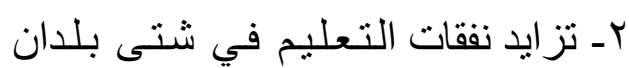
العالم في السنوات الأخيرة وضخامة مـاينفق عليه من الميز انيات العامـة للدول والدعوة إلى الموازنـة بين مـاينفق على التعليـ

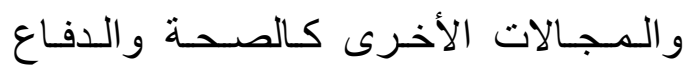
و المشرو عات الاقتصادية المختلفة. rـ عجز أغلب بلدان العـالم عن القيام بأعبائها التعليمية كاملة مما أدى إلى البحث اغث عن وسائل فنية لتقليل النفقات، وتوزيـهـا بهاتها بطريقة سليمة بين جو انب التعليم وميادينه. عـ التزايد الكبير فى أعداد الطلاب في

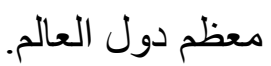

0ـ الحاجة إلى البحث عن مصادر تمويل مختلفه تغذي التعليم وتسد نفقاته، وحساجـاته.

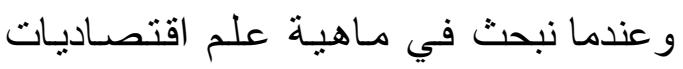

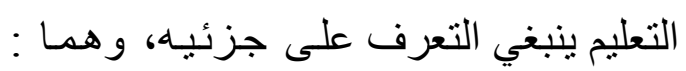
الاقتصاد و التعليم. فبينما يرنكز علم الاقتصاد على در اسه البدائل المتاحسة لإنتاج الموارد المرغوبة وتوزيعها فإن عملية التعليم هي لهي لهي حصيلة مايكتبه الفردمن معارف ومدعلوميات

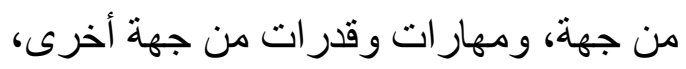

التربويـة والتعليميـة من خلال عمليـات

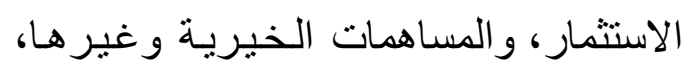

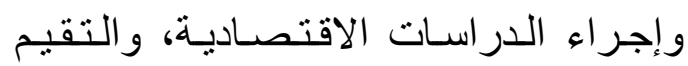
الاقتصـادي بـهدف رفع الكفاءه الداخليـة والخارجية. و هناك الفائدة وهى العائد المـادي الذي ينتج عن الخدمات التعليميـة سواء كان وهان المستفيد هو الفرد أو المجتمع بشكل عـام ؛ في فلكل عمل من قِبـل أي فرد عـائد مـادي أو لون معنوي يعود على الفرد نفسه، أو لغيره من فن فئن الأفراد، أو المؤسسات، او المجتمـع بصفة لـونة عامة. وحسب التقدير ات العالمية فإن العائد من رأس المال البشري يفوق العائد من رأس المال المادي بثثلاث مر ات على الأقل ومعدل العائد هو النسبة بين الفائدة المـاديـة والعـائد من برنامج تعليمي معين، وبين كلفة هذا

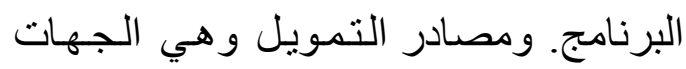
التي تتحمل كلفة الخدمات التعليمبـة ؛ وهى وهى

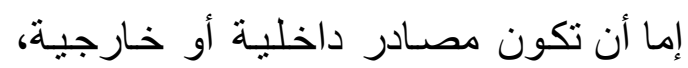

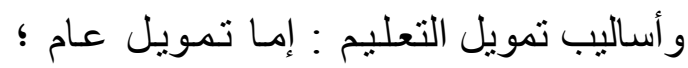
وهو المصدر التقليدي لتمويل التعليم، وهو أن تتحمل الدولة تحويل التعليم، ودفع كامل تكاليف العملية التعليمية من خلال ميزانيات

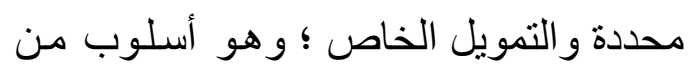
أساليب التمويل تتمثل في تحمل المجتمع دفع تكاليف تعليمهـم عن طريق دفع الطلاب رسوم للخدمات التي يحصلون عليها من الؤسسات التعليمية. و أسباب الاهتمام بدر اسـة 
الاقتصـاديـة كحسـابـات الكفاءة و الفـاعليـة باعتبار أن الاستثمار في التعليم هو الطريق للنمو الاقتصادي، وبمـا أن للتعليم بعدين أساسين فهو خدمـة اجتمـاعية من جهة، واستثمار في العنصر البشري من جهة أخرى ؛ ولـهـا فهو نشـاط ذو جدوى اقتصادية، و عليه فإن الاهتمام بتتمية الموارد البشرية أو التتمية البشرية لا يجب أن يقتصر

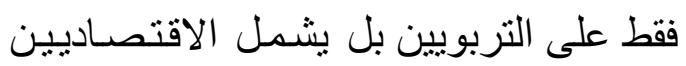
بنفس القدر أيضًا ؛ فالتعليم سبب التطور الاقتصادي ؛ وهو نتيجة لله أيضًا، و السؤال الذي بطرح نفسه الآن : هل المعـايير التي لتئه تعتمد عليها السياسات تختلف في وجهات

النظر بين التربويين والاقتصاديين ؟ إن تقيّم هذه السياسات يختلف في وجهات

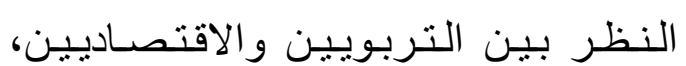
فالتربويين بؤكدون على أن مهمـة التعليم ليست فقط إعداد قوى عـاملـة مـزودة بالمعارف، والقيم اللازمـة للفرد كمواطن

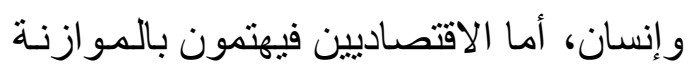
بين ناتج النظام التعليمي وحاجة سوق العمل، ومتطلبـات التنمية متفـادين هدر الموارد وتدني الإنتاجية، كما يحرصون على تحديد الأولويات واختيار البدائل الأكثر جدوى من الإنساهن

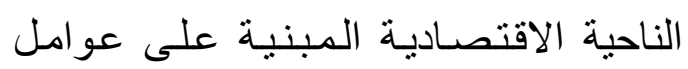
التكلفه و المنفعة . مفهوم اقتصساديات التعليم في الفكر
واتجاهات وقيم من جهة ثالثة، ويهذف التعليم إلى اكساب الفرد مهار ات ومعلومـات تؤهلـه لممارسة عمل معين، وتطوير إنتاجيته كمًا ونوعًا، وتلبيه احتياجات سوق العمل، وتتميـة المهار ات، والقدرات الإبداعية للار اسين إلى ولى أقصى حد تمكنهم قدر اتهم فيها، و عليه يصبح مفهوم علم اقتصاديات التعليم، واختيار البديل من البرامج التعليميـة الذي يحقق الأهداف

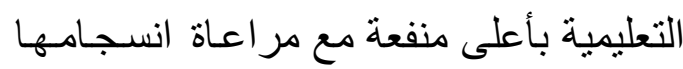

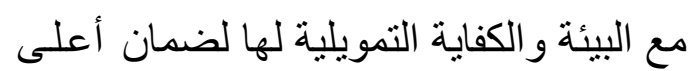
مردود ممكن بأقل تكلفة مدكنة أي أحسن مخرجات تعليمية بأقل مدخلات ممكنة وبنًاء على ماتقدم فان علم اقتصـاديات التعليم يقوم،

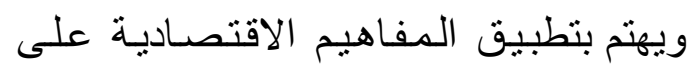
العمليات التربوية بالبحث الاقتصـادي ليتم تقويم التربية اقتصاديًا. كما أنه هو العلم الذي بالي

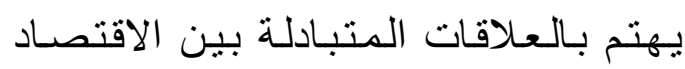
والتعليم ؛ وذلك لدور التعليم في النمو الاقتصادي من نـاحبـة ودور الاقتصـاد في ولي

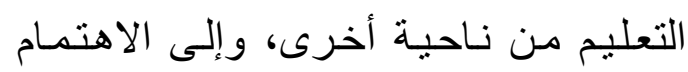
بتفادي الهدر فيما يُنفق على التعليم، مع التاكد من كفاءة النظام التعليمي، وجودة مدخلاتـه المختلفة، والاهتمام بتنـويع مصـادر تمـويل وحسل

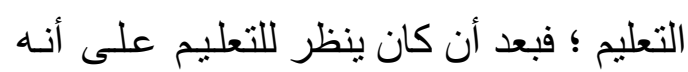
خدمة اجتماعية فقط أصبح ينظر إليه كعملية استثمارية في العنصر البشري تخضع للربح والخسـارة، وتر اعى بــض الــــاييـر 
المجتمع و الحكومة أن تتحمل نفقات الأعمال

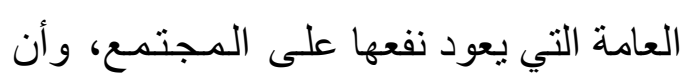

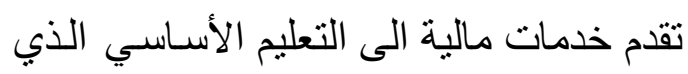

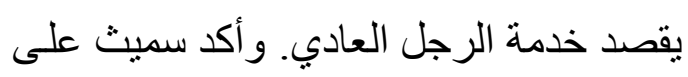

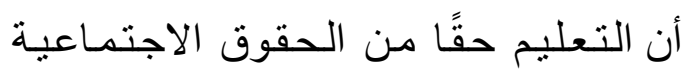
للأفر اد؛ وهو كذللك مسألة أخلاقية مؤكدًا على ضرورة التعليم الأساسي وطالب بأن

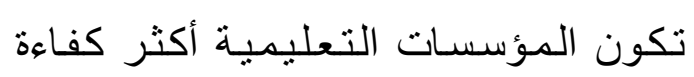

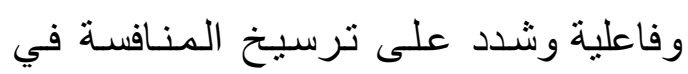

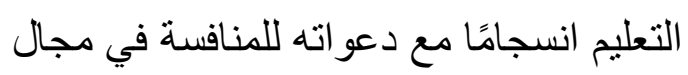

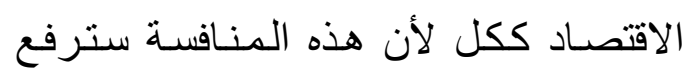

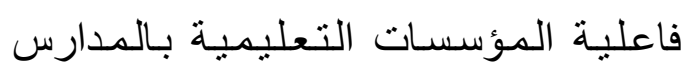

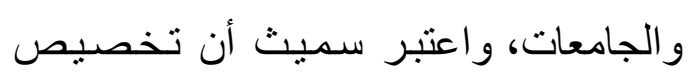

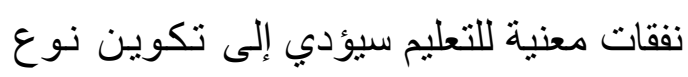

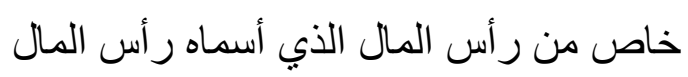

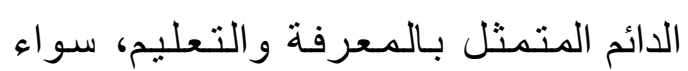
للأفر اد أو للاولة، وستكون هذه الثروة ملكًا

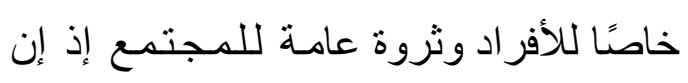

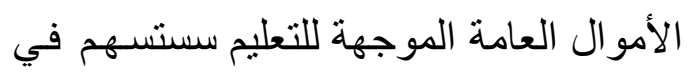

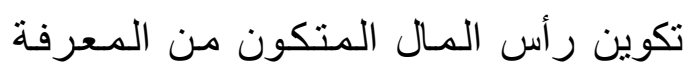

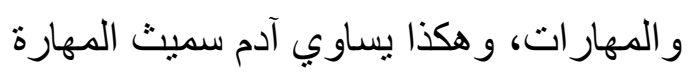
بالعوامل الأخرى التى تدخل في العملية

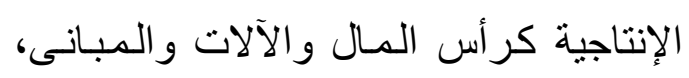
ولهذا فإنه برى بأن الاستثمار في التعليم ضروري لزيادة فاعلية القوى العاملة، ويؤكد

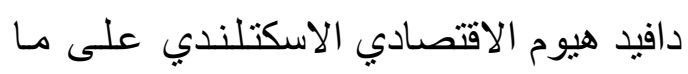

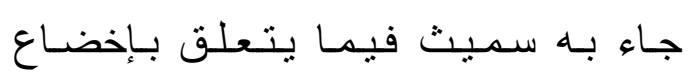

الاقتصادي : من الجدير بالذكر أن البحث في

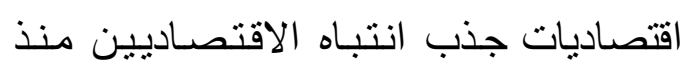
منتصف القرن المـاضي نتيجة احتدام

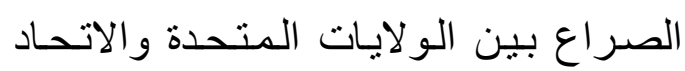

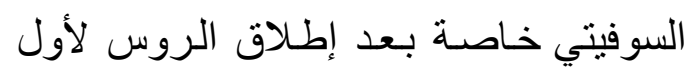

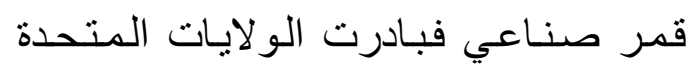

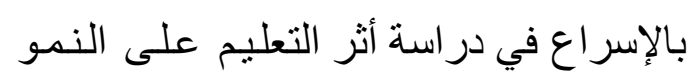
الاقتصـادي، ولقد نشرت بعض درالئر الأبحاث

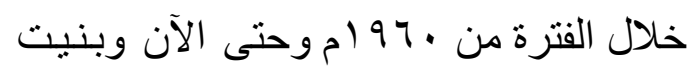

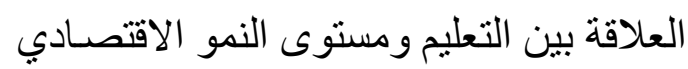

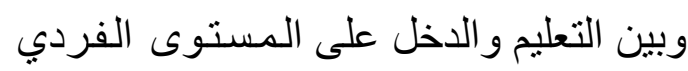
و القومي، وشرع كثير من الاقتصاديين خلال الستينيات و السبعينيات من القرن الماضي في الني وضع نماذج نظرية تنظر إلى التعليم بوصفه

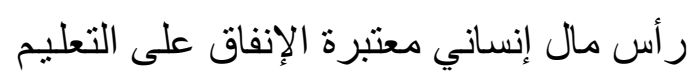

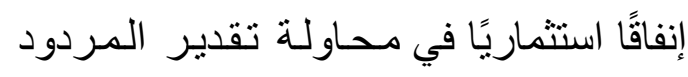
الاستثماري للإنفاق، ولقد أثبتت كل هذه

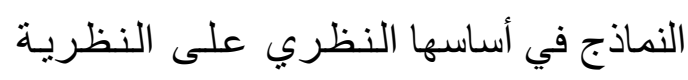

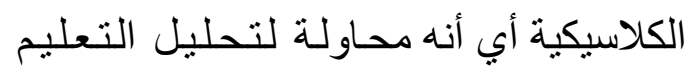

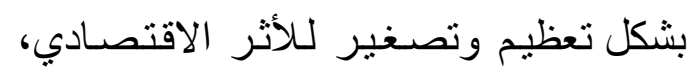

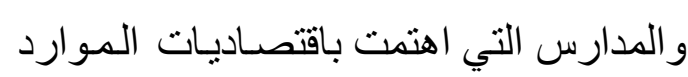

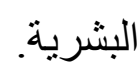
أولاً : المدرسة الكلاسيكية :

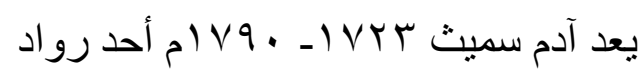
هذه المدرسة ؛و الذي اعتبر أن رأس المسال

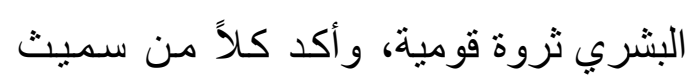

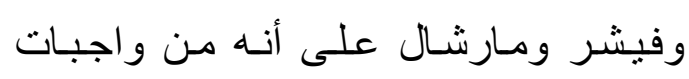


المؤسسات التعليمية للمنافسة، كما هو الحـال إنتاجيته.

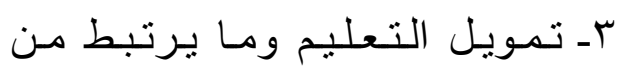

محاو لات إيجاد مصادر بديلة لتمويله.

ويمكن استخدام علم اقتصاديات التعليم في

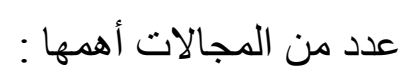

ا ـ تحديد أمثل الطرق لاستخدام الموارد

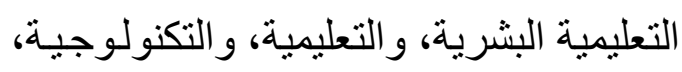

و الزمنية المناسبة.

r - تحديد تكلفة مر احله، و أنواع التعليم

المختلفة للمستقبل القريب و البعيد على ضوء

$$
\text { مؤشر ات الحاضر. }
$$

بـ در اسه الوضع الأمثل لحصة التعليم

$$
\text { في المز انية العامة لكل دولة. }
$$

عـ البحث عن مصسادر إضـافيـة إلى الى الى

ميز انية كل دولة ووفق ظروفها.

هـ در اسة كيفية توزيع ميز انية التعليم

$$
\text { علي مر احل وأنو اعه المختلفة. }
$$

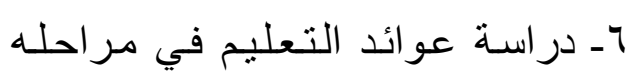

وأنواعه المختلفة آخذين عامل التكلفة بعين

$$
\text { الاعتبار. }
$$

Vـ در اسة الطرق التي تكفل زيادة كفاءة

و إنتاجية النظم التعليمية من المنظور الكمي.

كيفيه استخدام و استغلال الموارد البشريـة

حسب علم اقتصاديات التعليم : الإنسـان هو

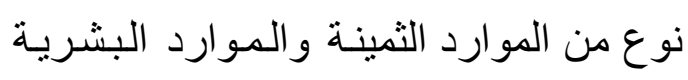
تحتاج إلى إدارة حكيمة مثل أي موارد أخرى
فى الاقتصاد لأنه يضمن إعطاء كفاءة أعلى.

ويربط الاقتصسادي الإنجليزي ديفيد

ريكارد ومؤسس المدرسة الكلاسيكية بين

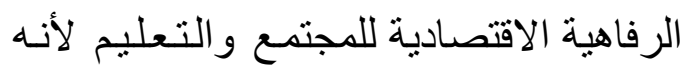
يساعد على زيادة الوعي.

ويقود إلى تنظيم النسل والتحكم في معدلات النمو السكاني.

مجالات البحث في اقتصاديات التعليم :

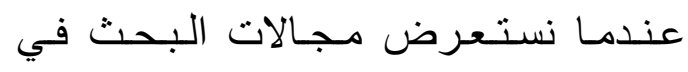
اقتصـاديات التعليم نجدها بدأت بشكل و اضتح

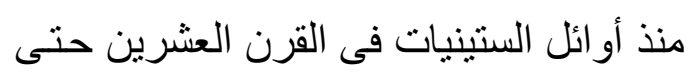

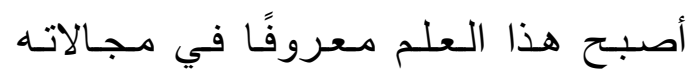
ونظرياته و على الرغم من ذلك فقد ازدادت هدي

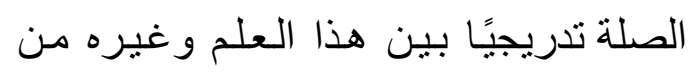
العلوم التربوية والاجتماعية الأخرى ويمكن عرض أبرز مجالات البحث في اقتصـاديات

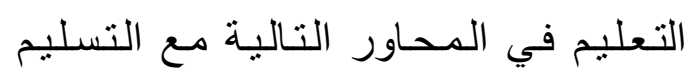
بالارتباط الكبير بينها جميعًا وذلك على النحو

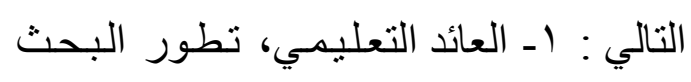

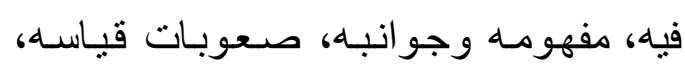
طرق قياس القيمة الاقتصادية للتعليم.

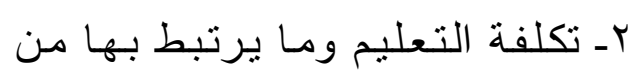
محاولات حديثة لخفض التكلفة من خلال تنـاول : التكلفة، وأسبـاب الزيـادة فيهـا، و المداخل المختلفة لخفضها سو اء من خـلال كلفة الوحدة أو من خلال زيادة كفاءة التعليم 
التنمية من بدايتها لنهايتها لأن دور الإنسان كمواطن في مجتمعه يتحقق، ويبرز أكثر

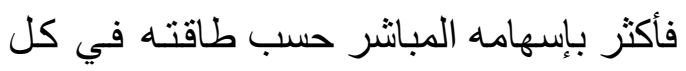

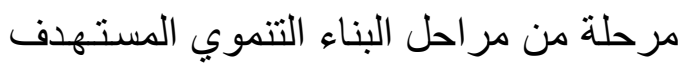
تحقيقه في بلده.

๑ـ تغيير أنماط حياه الفرد وتعديل أساليب حياته، و إنتاجه، وسلو كه للأفضل.

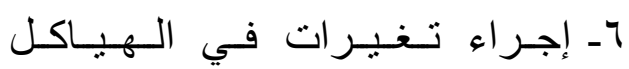
الاجتماعبه، والسلوكيه، و الثقافية، واهية والنظم السياسية.

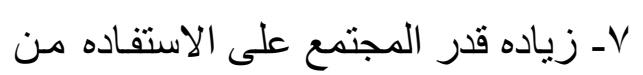

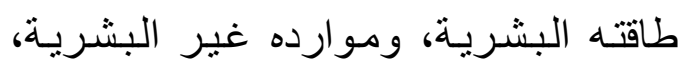

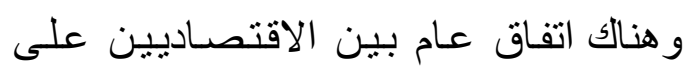

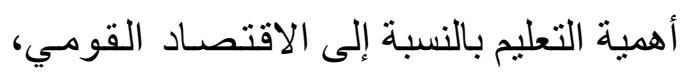

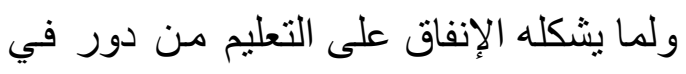

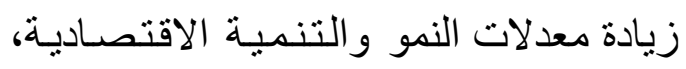
و التعلم من ضغط على ميز انية الدول.

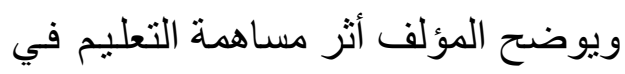
النمو الاقتصـادي من خـلال إبراز أهمية

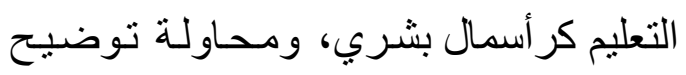
دور التعليم في تحقيق النمو الاقتصـادي لئي ويخلص إلى اعتبار نمو التعليم وتقدمهـ يزيد

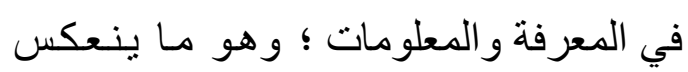

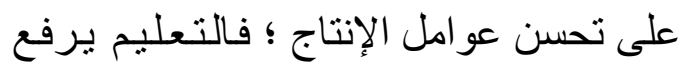

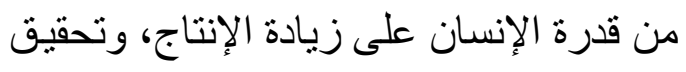
معدلات عالية للنمو الاقتصادي. فاليابان مثلاً

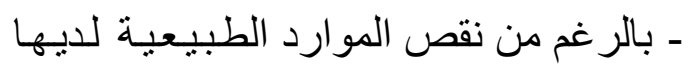

نادرة، و إدارة الموارد البشرية ذات وظائف

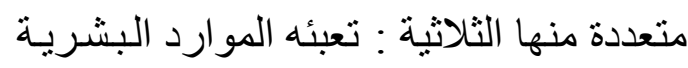
ذات وظائف متعددة منهـا الثلاثية، تعبئة المـوارد البشريـة (الحصـر والإحصــاء والتعرف على مختلف الخصسائص بالكم

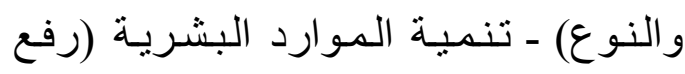
التوعية من خلال التعليم، الصحة، التغذيـة،

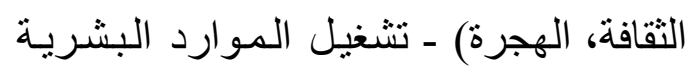

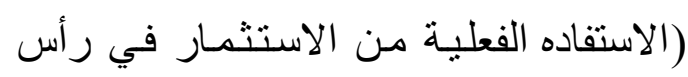

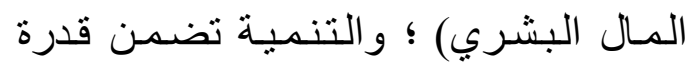

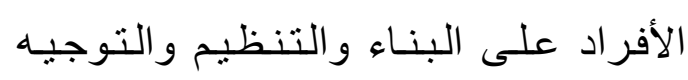

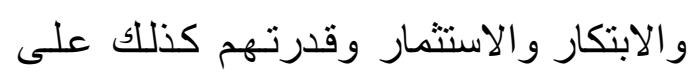
زياده حجم التعليم وتوسيعه بحيث يشمل كل ولان فرد مما يساعد على نموه، وبالتالي استثمار طاقات الأفراد و إنشر اكها في جهود نهود التنمية

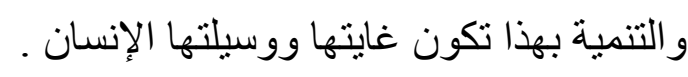
الأهداف العامة للتنمية :

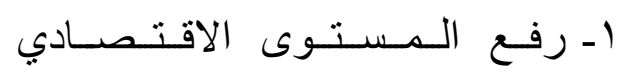
و الاجتماعي و الثقافة لاى المو اطنين وتحسين أحو الهم المعيشية. r- إثباع الحساجـات الأسـاسية لأفراد

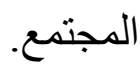
rـ تحقيق التجانس بين طبقات المجتمع ؛

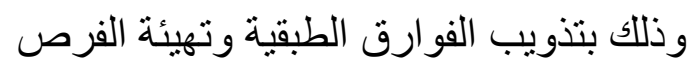
المتكافئة للجميع حسب قدر اتهم. عـ تأكيد المشاركة الثـعبية فى جهود فئه 
وعدم كفاية رؤوس الأموال - استطاعت مستحدثة.

الأهمية الاجتماعية للتعليم :

- إعداد و إنتاج العناصر القيادية.

ـ تكوين الإنسان المتحضر.

- زياده تمتع الانسان بحياته.

ـ تضييق حدة الفجوة الحضارية.

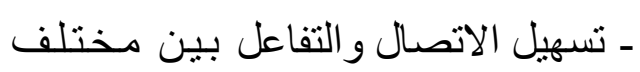

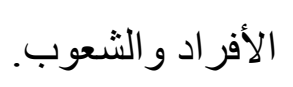

- زيادة طموح الأفر اد ودفهم إلى الصعود

$$
\text { في السلم الاجتماعي. }
$$

- يحفز العقول و النفوس ويزيد استعدادهـا لتقبل التغير و إحداثه.

- يوفر مناخ ثقافي للأفر اد و المجتمع. التعليم والتنـميـة البشريـة : التربيـة أو التعليم وسيلة لتنميـة القوى البشريـة التي تصنع التنمية وتحدد معالها بل إن أهم معسالم التنمية هو تتمية القوى البشرية. وهناك رأي آخر أن مفهوم التنمية أكثر ارتباطًا بـالتعليم لـئي وليس بالتربية ؛ فالتربية مفهوم أوسع وعام وشامل ؛ إذ تقوم بتنميـة الفرد من جميع جو انبه الروحية و الخلقية، و الاجتمـاعيـة، و الثقافية، و السبياسبـة وشكل سـليم ليكون

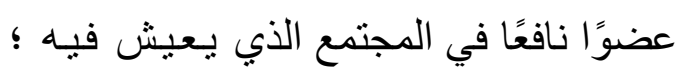
وهي أشمل بكثير من التعليم إذ بشمل الأسرة

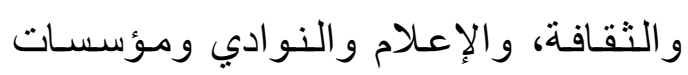
العبادة ........الخ. بينما التعليم هو عملية ولية

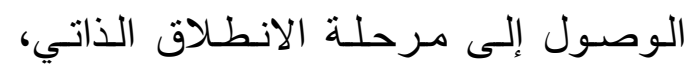

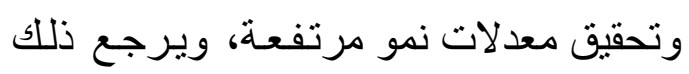
إلى أثر التعليم ودوره في الاقتصاد الياباني. اما معظم الدول العربيـة فتعـاني ضـف

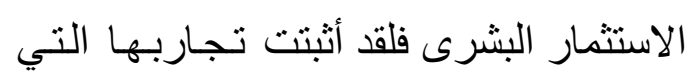
ركزت على الاستثمار المـادي فثل هذا الأسبوع في تحقيق التنمية الموجودة. الأهمية الاقتصادية للتعليم : نوفير فرص الاعن

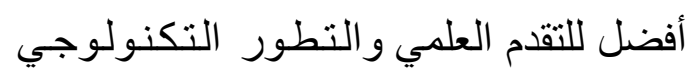

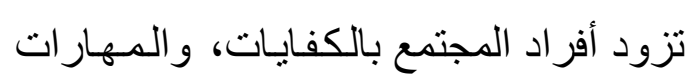
الفنية و التكنولوجية المطلوبة للتنميـه - يزيد برديد الطلب على السلع و الخدمات ـ تهيئه وسـئل التفكير الموضوعى و اكتشاف قدر ات الافر اد ـ مساعدة الأفر اد لتقبل التغير و أحداثه. ـ مفهوم التتميه الاجتمـاعية : التحسن المستمر لمستوى معيشة ورفاهيـة السكان ؛ وهى تعمل جنبًا إلى جنب مع التنميلة ورية الاقتصادية، منهج علمي وو اقعي لدراسـة

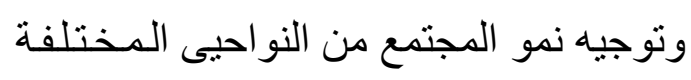
مع العناية بالجـانب الإنسـاني بغيـة إحداث

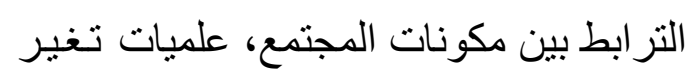

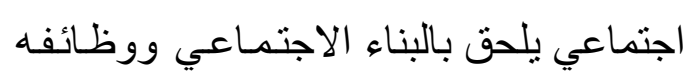

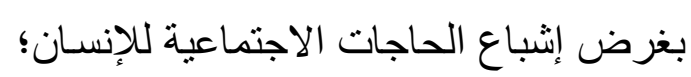
وهي لذلك تشمل عنصرين أسـاسيين هما بـاعيا تغير الأوضاع القديمة و إقامة بناء اجتمـاعي جديد تنبثق عنه علاقات جديدة، وقيم و أفكار 
طبيعة وماهية ومضمون هذا الاستثمـار ؟ وقضيـه الاستثمـار في التعليم هي شـأن شخصسي أو فردي أو مؤسسي كالجهات و القطاعات الخـاصـة، ويتوقف القرار في فولي الاستثمار في التعليم العالي على طبيعـة الجهة التي تر غب في الاستثمار. فمثناً بنظر القطاع الخاص إلى قرار الاستثمار على أنه قرار عقلاني يوازن من وجهة نظره مـا بين

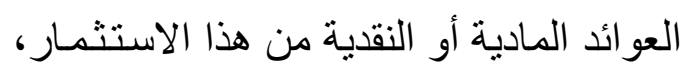
وبين مايتكبده من تكاليف مباشرة من معدات

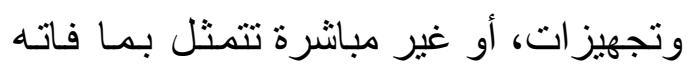

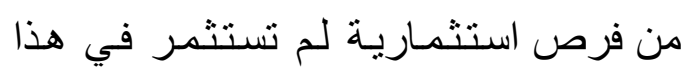
النشاط (تكلفة الفرصة البديلة) فيقوم بخصم

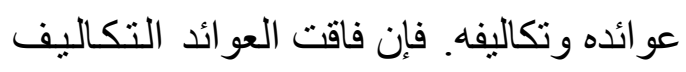
قام بالمشروع وبعكس ذلك لا يفعل. أمـا القرار الحكومي في الاستثمـار في التعليم فينظر إليه من زاوية كونه سلعة عامـة ليس للعو ائد و التكاليف المادية (النقديـة) الاعتبـار الأول كالقطاع الخاص. ومايهم المستثمر هنا معدل العائد الاجتمـاعي الذي يبحث في تحقيق أهداف عامة للمجتمع و الإنسـان تتسم بـالديمومـة، والتجدد المستمر كتعزيز الإنتاجية، وصقل المهار ات، والحفاظ على

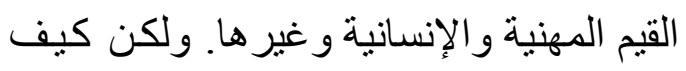

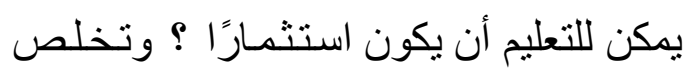

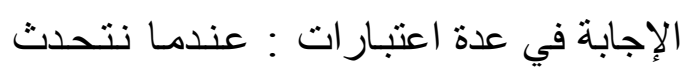
عن الموارد البشرية فإننا نعني الناس الذين
مقصودة توؤدى بو اسطة مؤسسـات أنشئت

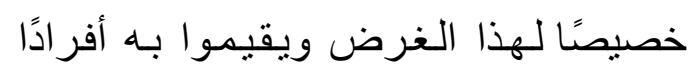
اختيروا، ودربو ا خصيصًا للقيام بهذه العملية بهدف الحصول على معرفة و اكتساب مهارة أو لتتمية قدر ات أو طاقات خاصة، وبـالتالي معرفي

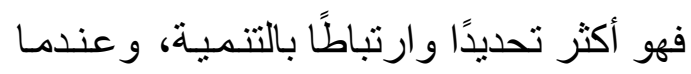
تشير الكتابات إلى التنميـة والتربيـة فإنها تقصد بذلك التعليم ـ وقد أثـار الكاتب في لتئي بحثه المعنون ب (التعليم والتنمية البشريـة) إلى أن كثيرًا من الدراسات تنظر إلى التعليم على أنه : يرفع الإنتاجية و يرفع الاستثمـار

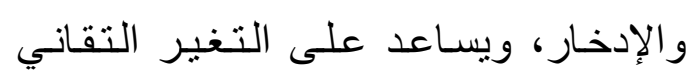
التكنولوجي، ويسهم بالتأثنر على المهـار ات ولات

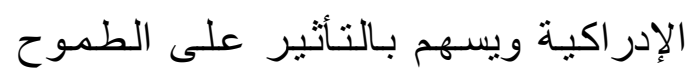

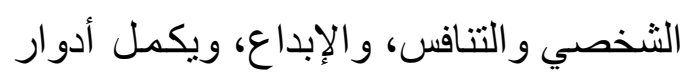

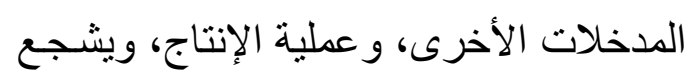
إسهام المر أة في النشاط الاقتصادي و العمل ولهل بآخر )، ويرفع تعليم الأبوين ونوعيـة الطفل

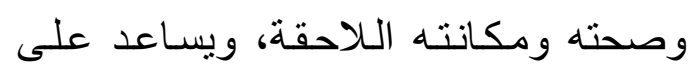
تحسين وتوزيع الدخل وتكافؤ الفرص . الاستثمـار في التعليم والعائد فيـه :

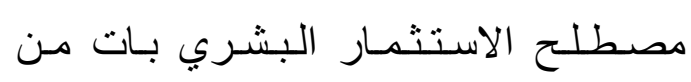
المصطلحات التي تفرض نفسها على السطح منذ بداية القرن العشرين لا سيما عند الحديث

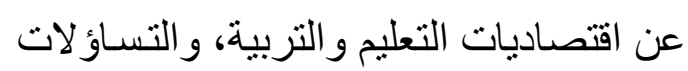

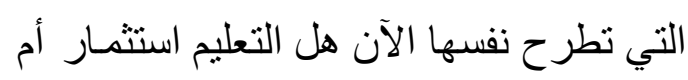

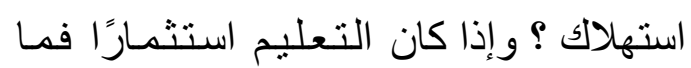


و السن، و العرق. وعلى ذللك فإن الانفاق على التعليم يؤدي إلى إنتاجية أفضل، ودخول أعلى ومن ثم يعد التعليم استثمـارًا طويل إلتاجيل المدى يتجسد في الثورة البشرية، ويدر عو ائد اقتصادية أكبر من الاستثمار في رأس المـال

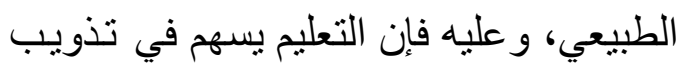

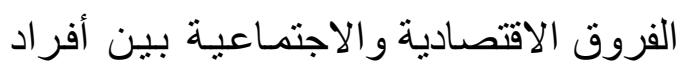

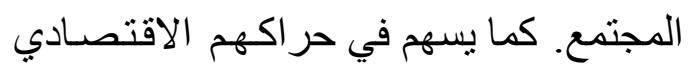

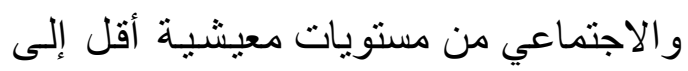
مستويات أعلى و أفضل على المدى الطويل

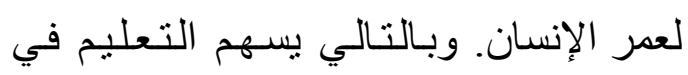
الدخل القومي، وفي معدلات التنمية لإنهية

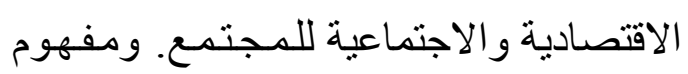

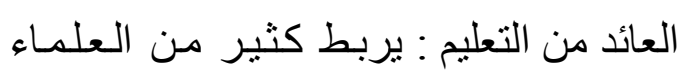

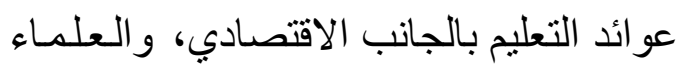

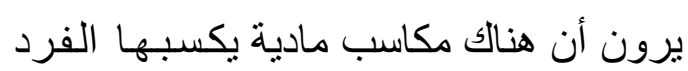

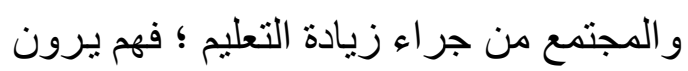

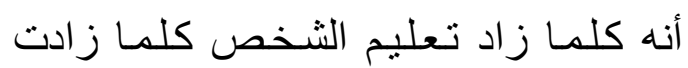
إنتاجيته، وبالتالي ز اد دخله مما يترتب عليه

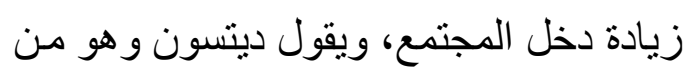
علماء اقتصاد القرن العشرين : إن العائد من

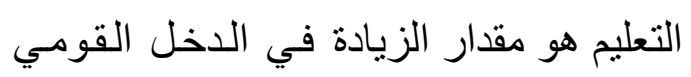

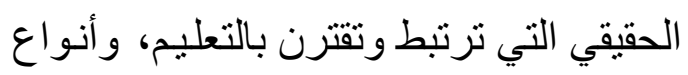
عو ائد التعليم عديدة، وتتدخل فيما بينها ترنها وأهمها :

ا ـ عو ائد اجتماعية، وعو ائد اقتصـاديـة،

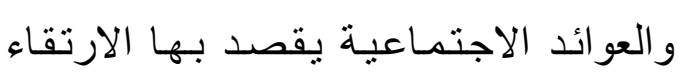

يعيشون في أمة أو مجتمع معين و هم يشكلون

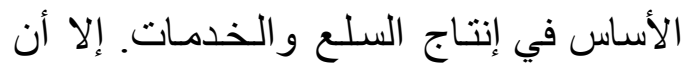

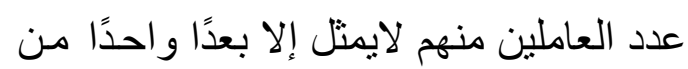

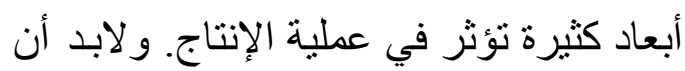
نضيف إلى ذلك نو عية العاملين ومجهوداتهم وتتاسقه. هكذا فإن الأمو ال التي نضعها في في وني

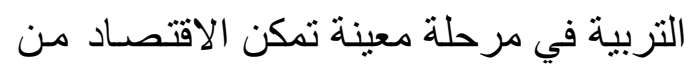

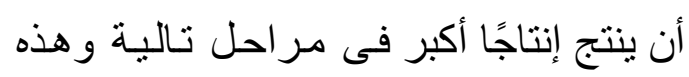

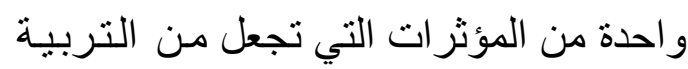

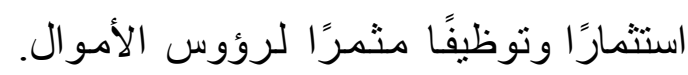
وقد أكدت الدراسـات على أن العلاقة بين الأنين

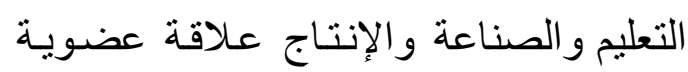

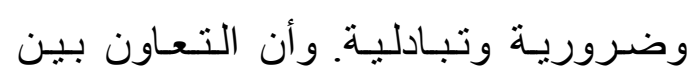

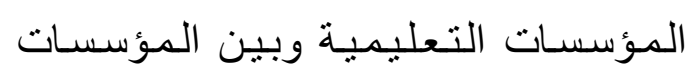
الإنتاجية لازم وحتمي. و العلاقة بين التعليم

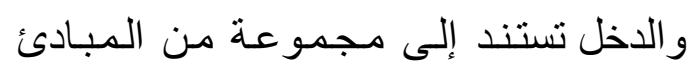

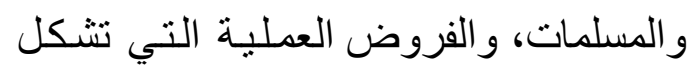
نظرية رأس المال البشري و التي مؤداهـا أن

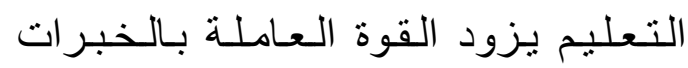

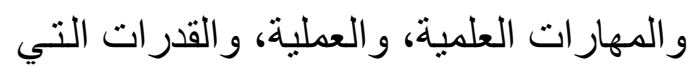

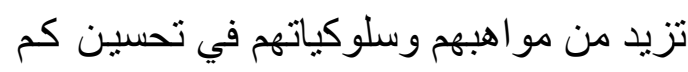
وجودة الإنتاج، ومـن ثم ترتبط القيمـة فئة الاقتصادية للتعليم على مستوى الفرد أون فئون

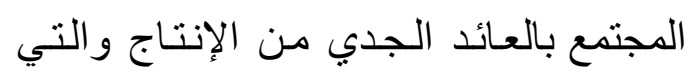

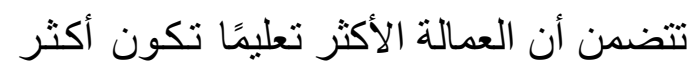

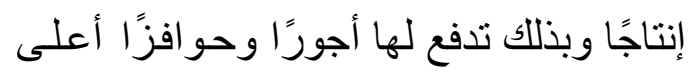
مع ثبات العوامل، الأخرى مثل : الجنس، 
العو ائد الاستهلاكيـة هى تللك العوائد التي تجنى منفعتها حالاً، ومن أمثلتهـا : (فرصـة الوالديـن لـارتيـاح مـن متـاعب الأبــاء بإرسالهم للمدرسة، وسرور هم بتفوق أبنائهم. و عو ائد رأسمالية وهي تللك النافع التي تجني لتئي في المستقبل، ومن أمثلتها الزيادة المنتوقعـة فئس في دخل الفرد و المجتمع الناتجة عن الانتظـام في الدر اسة وترك سوق العمل).

ع- عوائد النقدية وعوائد غير النقديـة :

العوائد النقديـة هي الأربـاح التي يجنيهـا المتعلم في المستقبل من جر اء زيادة تعليمـه، وتكوين عادات الاستهلاك الرشيد التي توفر جزءً من دخل الإنسان ليتم استثمـاره. عو ائد

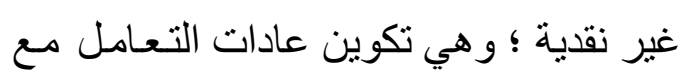
الآخرين كالأقارب و الجير ان، وقدرة الأفر اد

$$
\text { على الإبداع و الابتكار. }
$$

0ـ العوائد الأمنية للتعليم : إن التعليم

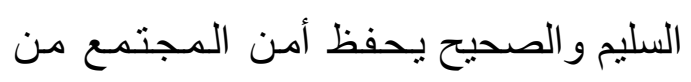
خلال تكوين المفاهيم السليمة نحو أمن أفراد

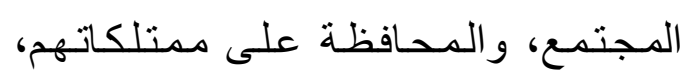
و أمو الهم و أعر اضهم، و عقلهم ودينهم، فالفرد

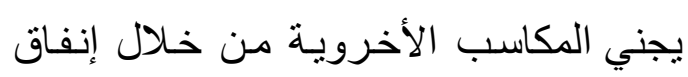
جهده وماله في سبيل العلم و المعرفة ؛ فقد

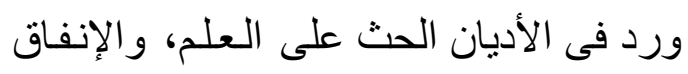
عليهـ. وقد كـان بعض السـلف الصـالـح بسافرون السفر الطويل من أجل تحصيل حديث، أو فهم آية و لاشك أن ذلك يتطلب بذل من لت
المعرفي لأبناء المجتمع، وتنظيم الحياة بين

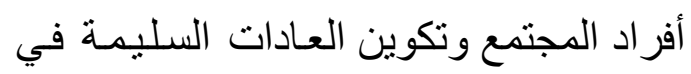
التعامل بين أفراد المجتمع، ومـع أنظمته ونه و القضاء على الجهل والأمية، وتكوين قيم التعامل مع الآخر، وقيم الحوار والاحتر ام

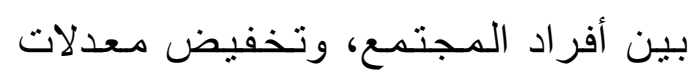
الجريمة، وحفظ أمن المجتمع، و القضاء على ولى لئ

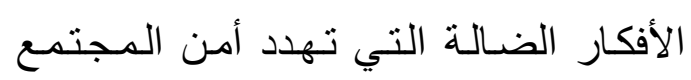

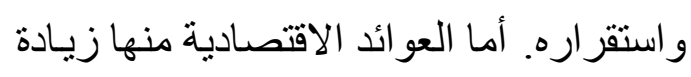

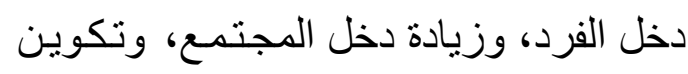

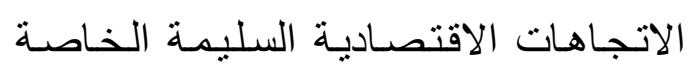

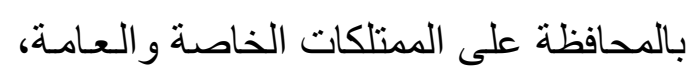

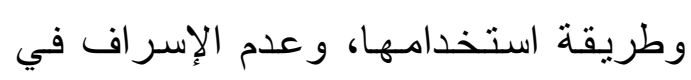
استخدامها. r- عوائد على مستوى الفرد و عوائد

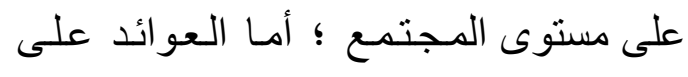
مستوى الفرد منهـا زيـادة دخل الفرد من من جر اء زيادة تعليمية، المكانة الاجتماعية التي

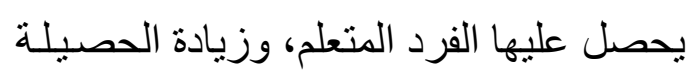

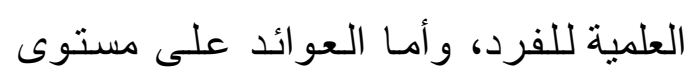

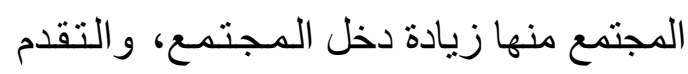

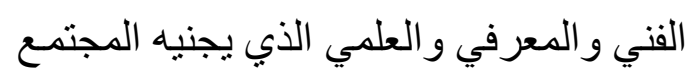
من جراء زيـادة تعليم أفراده، ومستوى

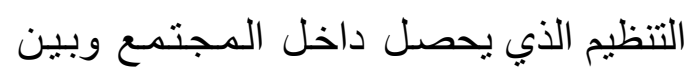
أبنائه علاوة على تكوين الاتجاهات السليمـة لاتئة نحو مقدرات وموارد المجتمع. بـ عو ائد استهلاكية وعو ائد رأسمـالية : 
الاجتماعية التى يحصل عليها الفرد كلما تقام

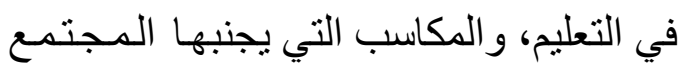
من خـلال الابتكار والتطوير المـرتبط بالتعليم؛ وهذا يؤيد وجهة النظر الثنانية.

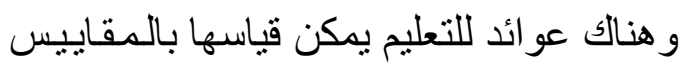
الاقتصادية ومن أمثالها المكاسب المالية التي ليكي

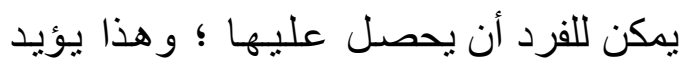

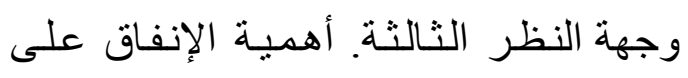

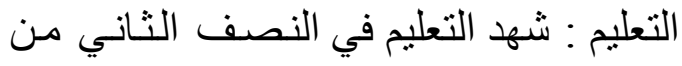

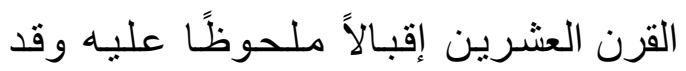
تطلب زيادة هذا الإقبال زيادة الإنفاق عليه لما ينطلب ذلك من توفير أبنية مدرسية،

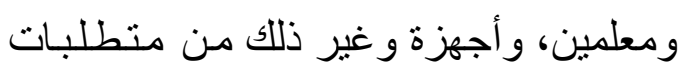

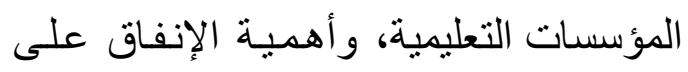
التعليم تقاس بقدر مايرصد كنسبة من ميز انية

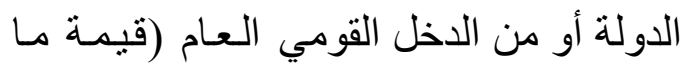

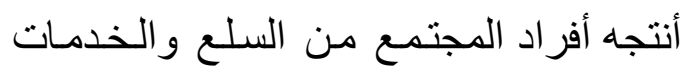

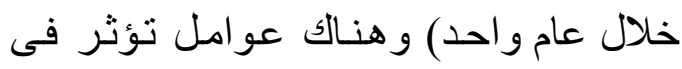
الإنفاق على التعليم : عوامل خارجيـة خـارج

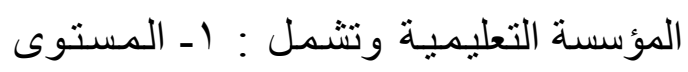

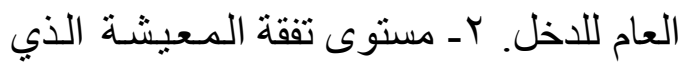
يدخل في تحديد أسعار السلّع و الخدمات.

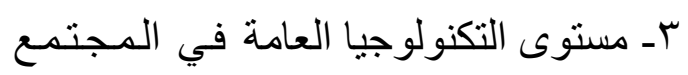
الذى يؤثر في المستوى التكنولوجي

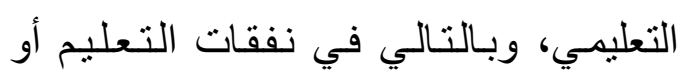

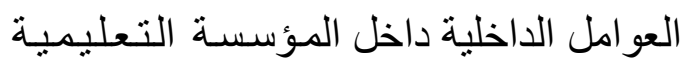
وتتـمل : ا-مستـوى أجور العـاملـين
مو ارد كثيرة. فالفرد المتعلم يعرف كيف يبعد

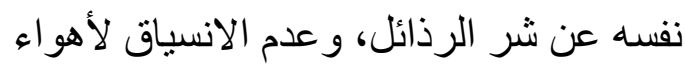
الثنيطان، والبعد عن ارتكاب الجريمة، الترانة

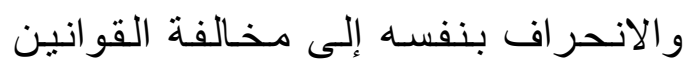
و التشريعات المنصوص عليها. قياس العائد من التعليم : هنالك جدل

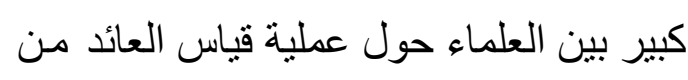
التعليم ؛ فهناك فريق يرى أن التعليم قيمة

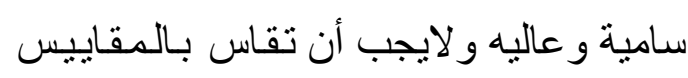
الاقتصادية لكي لا يفقد التعليم قيمته السامية العالية، و هناك فريق آخر يرى أنه يمكن لالتهن

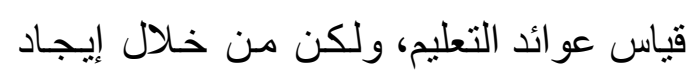

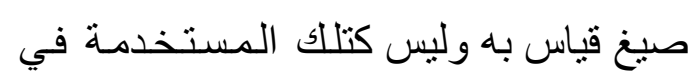
الاقتصاد، وفريق ثالث يرى أنه بمكن قياس المبل عو ائد التعليم، ويمكن استخدام أساليب القياس

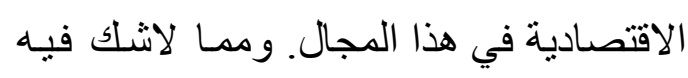

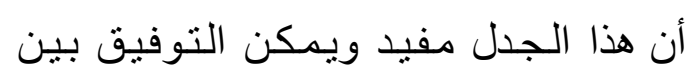
وجهات النظر الثناث ؛ حيث إن هناك عو ائد الندان للتعليم لايمكن قياسها، و لا يمكن أن تقدر التهر

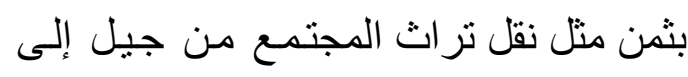

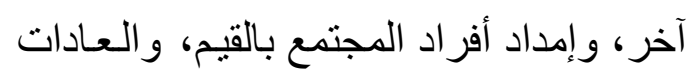

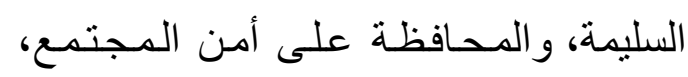

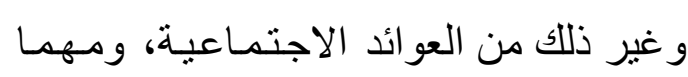

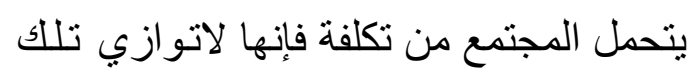

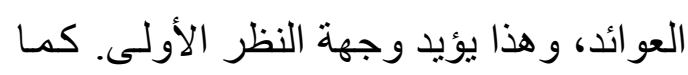

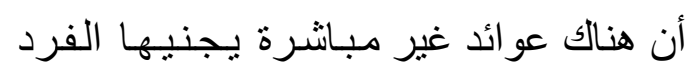
والمجتمـع من التعليم مثل : المكانة 
المستوى العـام لأسـعار التعليم ولاسيمـا رواتب المعلمين، وكذلك اتسـاع التعليم وشموله ميادين أوسع و الزيـادة الكبيرة في

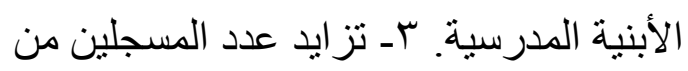
الطلاب، وكذلك ارتفاع منوسط حضور الطلاب إلى المدرسـة كل ذلك أدى إلى ملى

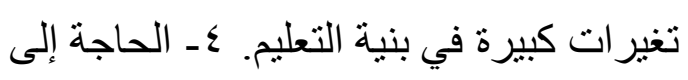
تحسين إعداد المعلمين وتدرييهم . تمويل التعليم : يؤكد الكاتب بداية أن التعليم يحتاج إلى تمويل جيد إذ إن جودودة

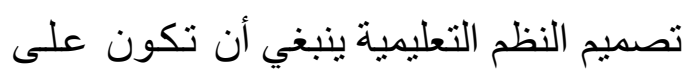
درجة من الكفاءة العالية في الإدارة و المنهج،

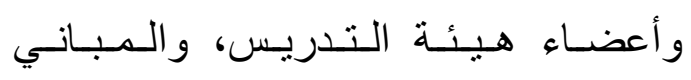

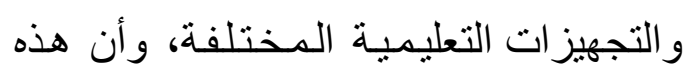

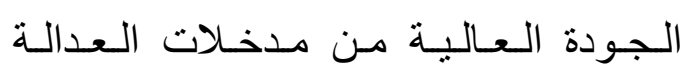
الاجتماعية يصعب تحقيقها أو الوصول إليها ملها ما دامت فرص التمويل الجيد أي توفير الأمو ال اللازمة للوفاء بالالتز امـات العلميـة التعليمية. وفي ضو ه تعاظم مفاهيم العائد من بن التعليم، وفي ظل الأزمات الاقتصادية، وندرة الموارد، والانفجار السكانى، وما يستتبع ذلك ولك من تزايد تدفق الطلاب على التعليم إلى جانب تز ايد كلفة التعليم بشكل مستمر تزداد

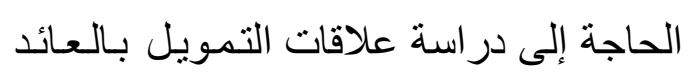
كر ابط حيوي بين مدخلات أي نظام تـعليمي

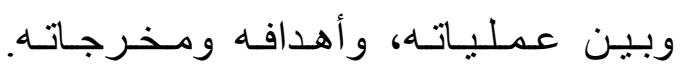
و المقصود بتمويل التعليم هو توفير الموارد
بالمؤسسات التعليمية. rـ التوزيع العمرى لهيئات التدريس ؛ حيث يؤثر فى مستوى الأجور. r- مستوى التكنولوجيا التعليميـة. عنصاب المدرس من ساعات التدريس.

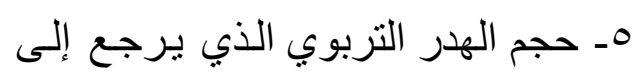
عاملي الرسوب و التسرب في أغلب الأحيان. ويتبين مما سبق أن الإنفاق على التعليم

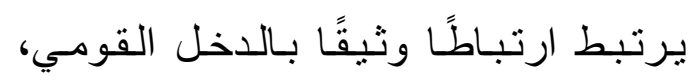
ومستوى المعيشـة، وكذلك أسعـار السـلع و الخدمات، و المستوى التكنولوجي العـام في ومي المجتمع ؛ حيث يزداد معدل الإنفاق كلما زاد الدخل القومي للبلد بينما يؤثر سلبًا في ارتفاع

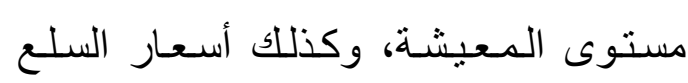
و الخدمات على مستوى الإنفاق فيؤدي إلى ولى تذبـذب نسـب الإنـفـاق مـا بــن الزيـادة و النقصسان؛ و التي لا دخل للمؤسسة التعليميـة فيها مما يؤدي إلى اختلاف مخرجات التعليم من سنة إلى أخرى حسب ما يقتضيه الوضع. أسباب زيادة الإنفاق على التعليم : هناك الك عدة عو امل مختلفة ومتباينة التأثير في حجم الإنفاق على التعليم سو اء كانت تمس التعليم يشكل مباشر و غير مباشر ومنها :

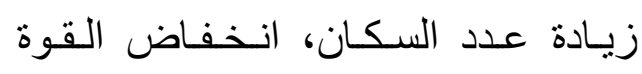
الثر ائية، كمية الخدمات التعليمية ونو عياتها. التغير ات في مستوى الأســار، وارتفـاع 


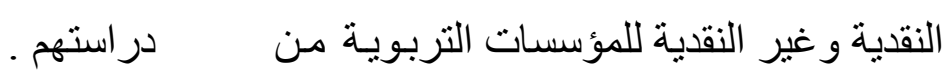

rـ التبر عات والهيئات المحلية ؛ فقد

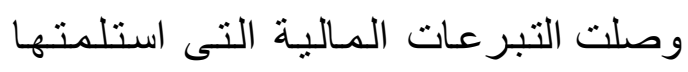
جامعة بكين من أثرياء هونج كونج حو الي عشرة ملايين دو لارًا أمريكيًا.

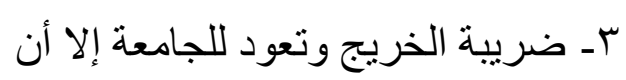

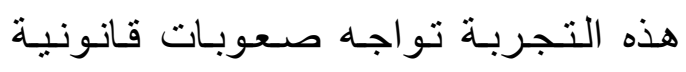

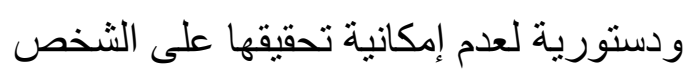
الموظف ذاتيًا. مصادر مختلفة، والتعليم يستمد موارده الماليـة من : المصـادر الحكوميـة ؛ ويتم التمويل الحكومسي في عدة أثنكال منهها : تحويل حكومي مباشر من طريق الواردات الثابتة المنتنظمة للدولتة (إيرادات الدولـة) وذلك من خلال ميز انية تخصص من الدخل

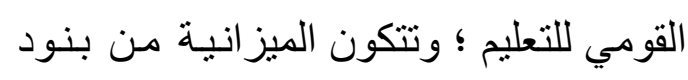

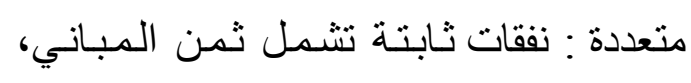
و المعدات، و التجهيز ات، و الأثاث، ونفقات دورية وتشمل : المرتبات والأجور، ونفقات والتهات ونهات

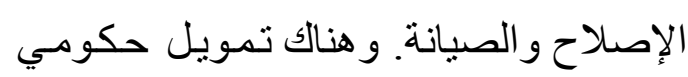
غير مباشر مثثل : فرض ضر ائب ورسوم خاصة للتعليم ؛ حيث تفرض بعض الحكومات ضر ائب على في

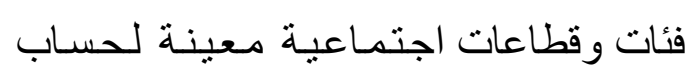
مؤسسات التعليم المختلفة ؛ ففى بريطانيا

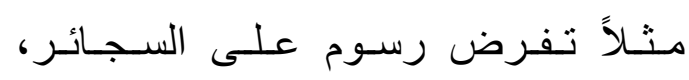
و المشروبات الكحولية لتمويل التعليم العـالي.

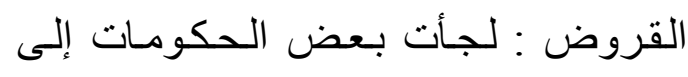
الاقتر اض لتمويل التعليم. وهنـالك تسـهيلات

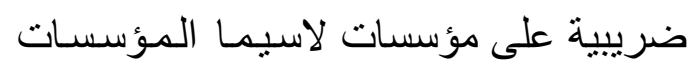

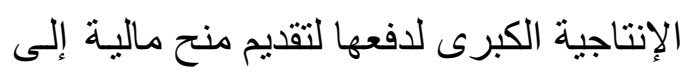

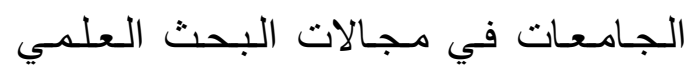
المختلفة، أو تبر عها بأجهزة ومعدات أو أي تسهيلات أخرى وهناك مصادر خاصة مثل : ا ـ الرسوم الدر اسية على الطلبـة مقابل 